\title{
APOIO À GESTÃO DE PAGAMENTOS PARA UMA UNIVERSIDADE FEDERAL: PROPOSTA DE UM MODELO MULTICRITÉRIO CONSTRUTIVISTA*
}

\author{
VINICIUS ABILIO MARTINS* \\ SANDRA ROLIM ENSSLIN" \\ LEONARDO ENSSLIN
}

Fecha de recibido: 26 de abril de 2017

Fecha de aprobado: 9 de abril de 2018

\begin{abstract}
Resumo
Esta pesquisa teve por objetivo construir um modelo multicritério de apoio à decisão construtivista para a avaliação de desempenho e o apoio das decisões relacionadas à gestão de pagamentos, da Universidade Federal da Integração Latino-Americana (Unila). Para esse objetivo, selecionou-se a metodologia multicritério de apoio à decisão construtivista (MCDA-C). Por meio de entrevistas semiestruturadas, 17 critérios (indicadores) foram construídos, o que permitiu uma avaliação global do desempenho, que indicou 21,89 pontos (em uma escala de 0 a 100). Em 6 dos 17 critérios, a Unila apresenta desempenho aquém das expectativas do decisor (chefe da Coordenadoria de Contabilidade e Finanças). A fim de evidenciar como o modelo pode apoiar as decisões da gestão de pagamentos, ilustrou-se o processo de criação de ações de aperfeiçoamento. O modelo construído incorporou aspectos singulares da Unila e ampliou as possibilidades de avaliação de desempenho $e$ o apoio a decisões relacionadas à gestão de pagamentos, fato não encontrado anteriormente na literatura.
\end{abstract}

Palavras-chave: gestão de pagamentos e caixa; universidades; avaliação de desempenho; abordagem construtivista; metodologia MCDA-C.

* Artigo de investigação científica.

** Doutorado em Contabilidade pela Universidade Federal de Santa Catarina (UFSC), em andamento. Mestre em Administração pela Pontifícia Universidade Católica do Paraná (PUCPR). Professor na Universidade Estadual do Oeste do Paraná (Unioeste). Endereço: Av. Tarquínio Joslin dos Santos, 1300. CEP 85870-650. Foz do Iguaçu-PR, Brasil. Telefone: (55 45) $3576-8155$. E-mail: viniciusabilio@gmail.com

**** Pós-doutorado pela Universidad de Valencia, Espanha. Doutora em Engenharia de Produção pela UFSC. Professora do Programa de Pós-graduação em Contabilidade e Engenharia de Produção (PPGC/UFSC e PPGEP/UFSC), nível doutorado. Endereço: UFSC — Centro Socioeconômico, Campus Universitário, Trindade. CEP: 88040-970. Florianópolis-SC, Brasil. E-mail: sensslin@gmail.com

**** PhD in Industrial and System Engineering from University of Southern California (UCS), Los Angeles, Estados Unidos. Professor do Programa de Pós-graduação em Administração da Universidade do Sul de Santa Catarina (Unisul), Florianópolis, Brasil. Endereço: Universidade do Sul de Santa Catarina, Departamento de Ciências Sociais Aplicadas, Programa de Mestrado em Administração. Rua Trajano, 199, Centro. CEP: 88010-010. Florianópolis-SC, Brasil. E-mail: leonardoensslin@gmail.com 


\title{
APOYO A LA GESTIÓN DE PAGOS PARA UNA UNIVERSIDAD PÚBLICA: PROPUESTA DE UN MODELO MULTICRITERIO CONSTRUCTIVISTA
}

\begin{abstract}
Resumen
Esta investigación tuvo como objetivo construir un modelo multicriterio de apoyo a la decisión constructivista, para evaluar el desempeño y el apoyo de las decisiones relacionadas con la gestión de pagos de la Universidad Federal de la Integración Latinoamericana (Unila), en Brasil. Con este fin, hemos seleccionado la metodología multicriterio de apoyo a la decisión constructivista (MCDAC). Por medio de entrevistas semiestructuradas, se construyeron 17 criterios (indicadores), lo que permite una evaluación general de los resultados e indicó 21,89 puntos (en una escala de 0 a 100). En 6 de los 17 criterios, la Unila tiene un rendimiento inferior de las expectativas del decisor (Jefe de Coordinación de Contabilidad y Finanzas). Con el fin de mostrar cómo el modelo puede apoyar las decisiones de gestión de pagos, se ilustra el proceso de creación de acciones de mejora. El modelo construido ha incorporado aspectos únicos de la Unila y ampliado las posibilidades de evaluación de desempeño y apoyo a decisiones relacionadas con la gestión de pagos, que no estaba previamente en la literatura.

Palabras clave: gestión de pagos y efectivo; universidades; evaluación del desempeño; enfoque constructivista; metodología MCDA-C.
\end{abstract}

\section{SUPPORTING PAYMENT MANAGEMENT AT A PUBLIC UNIVERSITY: A PROPOSAL FOR A MULTICRITERIA CONSTRUCTIVIST MODEL}

\begin{abstract}
This research intended to build a multicriteria constructivist decision-making support model to review performance and decision-making support related to payment management at the Federal University of Latin American Integration (UNILA) in Brazil. For this purpose, the Multicriteria Constructivist Decision-Making Support Method (MCDA-C) was selected. Using semi-structured interviews, 17 criteria (indicators) were laid down, which allowed an overall performance assessment and scored 21.89 points (on a 0-100 scale). In six of the 17 criteria, UNILA performs quite below the expectations of the decision-maker (Head of the Accounting and Finance Department). In order to show how the model can support payment management decision-making, the process of creating improvement actions is illustrated. The model created has incorporated unique aspects of UNILA, the expanding possibilities for performance review, and the support related to payment management decision-making, which was not considered in the literature.

Keywords: cash and payment management; constructivist approach; MCDA-C method; performance review; universities.

Martins, V., Ensslin, S. \& Ensslin, L. (2018). Apoio à Gestão de Pagamentos para uma Universidade Federal: Proposta de um Modelo Multicritério Construtivista. En: Revista de la Facultad de Ciencias Económica: Investigación y Reflexión. rev.fac.cienc.econ, XXVI (2), DOI: https://doi.org/10.18359/rfce.2855

JEL: M10, M40
\end{abstract}




\section{Introdução}

As organizações, independentemente do setor em que atuam, estão inseridas em ambientes cada vez mais dinâmicos (Martins, 2015). A gestão de caixa e pagamentos assumiu uma dimensão preocupante nesses ambientes dinâmicos, pois muitas organizações não estão adequadamente preparadas para realizar com eficiência e eficácia essa atividade rumo ao alcance da(s) meta(s) estabelecida(s) (Agandu, Okon e Robinson, 2007). Em casos extremos, a incapacidade de gestão pode ocasionar insucesso empresarial (Tran e Carmichael, 2013), o que torna a gestão de caixa e pagamentos um problema constante em todos os tipos de organizações (Moraes e Nagano, 2013).

A gestão de caixa e pagamentos preocupa-se com a gestão dos fluxos de caixa, seja por atividades operacionais da empresa, seja por transações financeiras que tenham sido negociadas (Moraes e Nagano, 2013), seja por saldo de caixa em determinados momentos (Agandu, Okon e Robinson, 2007). O decisor controla o processo de gestão de caixa, que inclui a coleta dos dados, a previsão e tomada de decisões, bem como os recursos corporativos dedicados a essas funções (Bell e Parker, 1985). O efetivo gerenciamento de caixa aumenta a flexibilidade $e$ a vantagem competitiva de um negócio ao lidar com situações de emergência ou ao aproveitar as oportunidades à medida que elas surgem (Enow e Kamala, 2016). Assim, a gestão dos pagamentos é um componente crucial do desempenho do fluxo de caixa das organizações (Chen, 2012).

A gestão dos recursos é uma dimensão sensivel da administração corporativa que as organizações, nos setores público e privado, precisam se reinventar, se quiserem, de forma efetiva e eficiente, avançar em suas atividades (Agandu, Okon e Robinson, 2007).

O uso de modelo para a tomada de decisão torna-se relevante, uma vez que ele pode fornecer uma visão abrangente e otimizada que, dificilmente, pode ser obtida sem o uso de metodologias para esse objetivo (Moraes e Nagano, 2013). Embora muitos estudos reconheçam a importância das condições de pagamento na gestão do fluxo de caixa, existe pouca análise ad hoc (Chen, 2012). Os trabalhos encontrados procuram apresentar modelos preditivos de gestão de pagamentos. No entanto, existem situações em que modelos genéricos acabam por não oferecer subsídios para a situação específica da organização, como é o caso da administração pública brasileira.

Nos últimos anos, o Brasil tem sofrido escassez de recursos, devido, entre outros motivos, à diminuição na arrecadação pública, situação que se agravou em 2015 e 2016. Em consequência, o serviço público brasileiro também é afetado com esse contingenciamento. Tais frustrações na arrecadação, por vezes, não são previstas, sendo então executado o orçamento, sem a contrapartida da arrecadação financeira.

Sob essa perspectiva, por mais que se preparem orçamentos e suas previsões, ou se monitorem os fluxos de caixa com base em tempo real (Enow e Kamala, 2016), as características subjetivas de cada cenário, ambiente, organização ou decisor não são levadas em consideração nos modelos anteriormente encontrados. Conjugadas a isso, situações que podem se caracterizar com uma combinação de diferentes atores, valores, percepções e objetivos, interagindo em relações assimétricas de poder (Tasca, Ensslin e Ensslin, 2012; Ensslin, Dutra e Ensslin, 2000), podem se tornar complexas por abarcarem múltiplos e conflitantes critérios (Tasca, Ensslin e Ensslin, 2012).

Nesse contexto, emerge a seguinte pergunta de pesquisa: quais critérios subsidiam e contribuem para melhorar a gestão de pagamentos e caixa em um ambiente de restrição financeira em uma instituição pública federal? Para responder a essa pergunta, este estudo tem o objetivo de construir um modelo multicritério de apoio à decisão, sob o viés construtivista, para a avaliação de desempenho e suporte às decisões relacionadas à gestão de pagamentos, da Universidade Federal da Integração Latino-Americana (Unila). Com o intuito de atender ao objetivo estabelecido, utilizou-se, como instrumento de intervenção, a metodologia Multicritério de Apoio à Decisão Construtivista (MCDA-C), por se tratar de um problema que abrange fatores 
sociais e necessariamente abordagem participativa dos gestores e dos atores envolvidos, sob o enfoque de um modelo não generalista (singular - ad hoc).

O presente artigo está organizado em cinco seções. Após esta seção introdutória, a segunda seção discorre sobre a base teórica que fundamenta o trabalho. Na terceira seção, apresenta-se a metodologia de pesquisa. A quarta seção descreve a construção do modelo multicritério de apoio à decisão do estudo de caso. A última seção tece as considerações finais da pesquisa; por fim, apresentam-se as referências.

\section{Referencial teórico: gestão de caixa e gestão de pagamentos}

As atividades de qualquer organização implicam o surgimento de fluxos de caixa, cuja eficiência $e$ eficácia dependerão dos métodos aplicados para gerenciá-los (Knyazeva et al., 2016). A gestão de pagamentos e caixa é uma parte estratégica do processo de administração financeira de todas as organizações (Agandu, Okon e Robinson, 2007) e lida com o uso eficiente dos ativos líquidos de uma empresa (Righetto, Morabito e Alem, 2016), sendo uma função importante que atrai recursos corporativos consideráveis dentro das organizações (Bell $e$ Parker, 1985).

O efetivo gerenciamento de caixa aumenta a flexibilidade e avantagemcompetitiva de um negócio em lidar com situações de emergência ou aproveitar as oportunidades à medida que elas surgem, em um curto prazo (Enow e Kamala, 2016). No entanto, problemas de gestão de caixa não são comuns apenas em organizações privadas. A negligência com a gestão do fluxo de caixa também é um problema comum em muitos setores públicos (Su e Hildreth, 2018).

Trata-se de tomar as decisões financeiras corretas em organizações de negócios, não comerciais, governamentais e entidades afins e tem-se como objetivo fundamental a ótima utilização dos recursos financeiros das organizações (Agandu, Okon e Robinson, 2007) em que o decisor controla o processo de gestão de caixa, incluindo a coleta de dados, a previsão e a tomada de decisões (Bell e
Parker, 1985). A gestão desses recursos pode ser considerada, operacionalmente, a alma das organizações (Agandu, Okon e Robinson, 2007).

O objetivo geralmente aceito de gestão financeira, de caixa ou de pagamentos de organizações com fins lucrativos é maximizar a riqueza dos acionistas pelo aumento do preço das ações da empresa (Strydom e Stephen, 2014). No contexto de uma organização sem fins lucrativos, que não têm acionistas e que têm como objetivo a prestação de serviços aos necessitados, em vez de buscar lucros, o modelo-padrão de gestão financeira não é tão apropriado, pois, nessas organizações, o objetivo da gestão é assegurar que as receitas possam ser mantidas para entregarem propósitos existenciais (Strydom e Stephen, 2014).

O problema da gestão do fluxo de caixa de uma empresa é um problema financeiro que envolve uma complexidade considerável para lidar com investimentos de curto prazo, recebimentos, pagamento de despesas, dívidas da empresa, a fim de maximizar o retorno financeiro no final de um horizonte de planejamento (Pacheco e Morabito, 2011). Esses problemas incluem considerações como o custo de oportunidade de manter recursos monetários versus o custo da penalidade de não ter dinheiro suficiente para atender às necessidades atuais; o custo incorrido ao fazer alterações nos níveis de caixa, aumentando ou diminuindo-os quando necessário; a incerteza do momento e da magnitude dos recebimentos e desembolsos de caixa, e o tipo de política de controle que deve ser usado para minimizar o nível exigido de saldos de caixa e custos relacionados (Caouch, 2018; Salas-Molina e Rodríguez-Aguilar, 2017; Salas-Molina, Pla-Santamaria e RodriguezAguilar, 2016).

Mesmo sendo um processo dispendioso (MossawiHaddar e Jaber, 2013), a importância das práticas de gestão de caixa eficientes e eficazes de empresas tornaram-se uma importante área de pesquisa nos últimos anos devido ao ambiente financeiro competitivo (Tahir, Alifiah, Arshad e Saleem, 2016). Na gestão financeira, o planejamento tático do fluxo de caixa é uma atividade crítica realizada para maximizar os recursos disponiveis e minimizar os custos 
financeiros resultantes da utilização de recursos de terceiros, quando necessários (Righetto, Morabito e Alem, 2016), para manter o ajuste de contas de negócios, financiar estoques e pagar fornecedores (Mossawi-Haddar e Jaber, 2013).

Assim, percebe-se que a gestão de caixa se constitui como uma atividade central para as organizações, uma vez que a gestão inadequada dos recursos financeiros, normalmente, são as principais causas de falência (Khanzadi, Eshtehardian e Mokhlespour Esfahani, 2017). Dessa forma, as organizações, para manterem sua posição no ambiente em que se inserem, devem prestar atenção especial à manutenção de um fluxo de caixa positivo estável e aos motivos de sua redução (Knyazeva et al., 2016).

A gestão de pagamentos de uma organização não influencia apenas a si mesma, mas também a seus relacionados. As condições de pagamento de organizações e fornecedores têm um impacto importante sobre o capital de giro das empresas contratadas (Chen, 2012). Além disso, quando os pagamentos são atrasados ou se tem à disposição menos do que o esperado, o fluxo de pagamentos aos fornecedores $e$ aos subcontratados são afetados, juros bancários podem ser adicionais, e, se o pagamento é encaminhado para a resolução de litígios judiciais, isso adiciona mais tempo e custo às organizações.

Algumas das preocupações relacionadas à gestão de pagamentos e caixa dizem respeito aos registros financeiros e contábeis incompletos e controles internos deficitários (Agandu, Okon e Robinson, 2007), além da quantidade de recursos líquidos que a organização possui (Mao e Sandali, 1978). A consequência de registros financeiros e contábeis incompletos resulta na descrença em como as despesas foram geradas, capaz de demonstrar tendência a fraudes (Agandu, Okon e Robinson, 2007). Em relação aos controles internos deficitários, estes dificultam fiscalizações e comprometem a gestão estratégica por meio da má gestão dos recursos financeiros (Agandu, Okon e Robinson, 2007). Ou seja, além das funções de rotina de pagar e receber, o processo necessita garantir a manutenção de bons registros financeiros e contábeis (Agandu, Okon e Robinson, 2007).
Uma boa gestão de pagamentos e caixa significa aumentar o controle, reduzir custos e maximizar o uso do dinheiro. Com vistas a essa maximização no uso do dinheiro, as empresas costumam investir seus recursos em ativos financeiros com diferentes períodos de carência para receber um rendimento maior em comparação com ativos que não têm nenhum período de carência para resgate (Righetto, Morabito e Alem, 2016).

A maioria das pesquisas, na literatura de gerenciamento de caixa, tem se concentrado em como determinar as disponibilidades "ideais" de caixa (Wang et al., 2018). Os primeiros modelos de cash management são encontrados em Baumol, em 1952, quando o dinheiro é considerado como item de estoque (Moraes e Nagano, 2013; Bell e Parker, 1985). Essa abordagem baseia-se na aparente semelhança entre a estrutura de custos da gestão de caixa com problemas de gestão de estoque, e muitos autores têm proposto modelos de gestão de caixa nos quais o dinheiro é considerado um estoque (Bell e Parker, 1985).

Nessa abordagem, o estoque de dinheiro é descrito por um fluxo descendente de recursos devido às despesas, até que um certo nivel baixo é atingido. Isso provocará uma conversão de ativos financeiros em dinheiro, a fim de elevar o estoque de dinheiro quando um novo ciclo começa (Bar-Ilan, Perry e Stadje, 2004), que tem determinados custos associados à sua origem e manutenção, mas também gera benefícios indispensáveis à empresa (Moraes e Nagano, 2013).

Para Miller e Orr (1966), a gestão de caixa é como um problema de carteira que a empresa deve equilibrar investimentos em dinheiro com participações em ativos que pagam juros. Assim, o problema de gestão de caixa tem sido visto como um problema de alocação dinâmica, que deve ser resolvido usando programação dinâmica (Bell e Parker, 1985). As empresas diferem em relação aos seus domicílios, influenciando seu fluxo de caixa diário, bem como as despesas diárias, sendo que grandes transações financeiras são mais prováveis (Bar-llan, Perry e Stadje, 2004). 
Baumol (1952) e Miller e Orr (1966) se preocupam apenas com a otimização da função administrativa do decisor em relação à receita recebida aos desembolsos em uma base periódica (Bell e Parker, 1985).

No entanto, a função de gestão de caixa, em grandes corporações, abrange muito mais do que isso (Bell e Parker, 1985). O gestor financeiro pode estar envolvido em manipular o fluxo de receitas por meio de termos das faturas, procedimentos de depósitos em dinheiro, além de poder controlar o fluxo de desembolso por meio da aprovação de grandes desembolsos (Bell e Parker, 1985). Ou seja, mesmo estando vinculado às entradas de recursos, o decisor tem o poder de direcionar para onde fazer os pagamentos.

Apesar de as organizações estarem dispostas a investir recursos em sistemas de gestão de caixa, tais como os sistemas de informação em tempo real (Bell e Parker, 1985), ainda existem organizações que buscam o acúmulo de recursos, com vistas a demandas futuras. No entanto, há um custo significativo associado ao acúmulo de fundos discricionários dentro da empresa (Luo, 2011).

Para as empresas que apresentam reservas de caixa maiores, é possivel supor que as restrições financeiras mitigariam o conflito de agência sobre a implantação de restrições de caixa (Luo, 2012). Gestores, quando controlados, podem apresentar interesses mais bem alinhados com os acionistas, porque se diminui o investimento ineficiente de dinheiro e, consequentemente, os benefícios privados no futuro (Luo, 2012).

Nesse sentido, existem evidências de que há benefícios na redução de recursos disponiveis nas organizações, já que os gestores não podem então desperdiçar dinheiro, em que restrições financeiras desempenham um papel disciplinador na dissipação de caixa na presença de problemas de agência (Luo, 2012). Concomitante, a gestão de pagamentos e caixa estimula uma contabilidade precisa, a divulgação adequada de entrada e saída e a busca por combinar manutenção de liquidez e rentabilidade com riscos operacionais reduzidos e custos minimizados (Agandu, Okon e Robinson, 2007). O pro- cesso envolve basicamente verificar, obter e manter os níveis de caixa realistas como e quando devido (Agandu, Okon e Robinson, 2007).

Para Luo (2012), quando uma empresa tem dificuldade em captar recursos externos, gestores são motivados a investir os recursos de forma eficiente, o que torna outros mecanismos de controle menos importantes.

Com medidas de proteção decisivas, dirigidas à melhor gestão dos ativos líquidos, é possível influenciar o crescimento e o desenvolvimento das instituições que, por sua vez, traduzirão para melhor qualidade de prestação de serviços e mais benefícios para o público, funcionários, governo e outras partes interessadas (Agandu, Okon e Robinson, 2007)

Em níveis profissionais mais elevados, é possivel que se exija a aplicação de complexos e sofisticados modelos financeiros de gestão (Agandu, Okon e Robinson, 2007). Pesquisas sobre gestão de caixa e gestão de pagamentos não apresentam uma definição comum dos problemas relacionados à gestão de pagamentos e caixa, mas sim são caracterizadas por uma grande variedade de definições do problema, hipóteses e técnicas de modelagem (Bell e Parker, 1985). Gestão de fluxo de caixa é relativamente bem pesquisada, e estudos anteriores tratam extensivamente de métodos para predizer fluxos de caixa (Chen, 2012).

Encontram-se pesquisas que relacionam preço de venda, gestão de fluxo de caixa e flexibilidade na capacidade de produção (Lusa, Martinez-Costa e MasMachuca, 2012), alocação de recursos em caixa e aplicações financeiras (Mao e Sarndao, 1978; Miller e Orr, 1966; Baumol, 1952), relação entre operações e o fluxo de caixa (Righetto, Morabito e Alem, 2016), previsões de recebimentos (Bar-llan, Perry e Stadje, 2004), fluxo de caixa e pagamento de projetos (Enow e Kamala, 2016), relação entre o fluxo de fundos entre as subsidiárias e os custos de transferência (Shapiro, 1978), maximização do retorno em dinheiro dos recursos financeiros no final de um multiperíodo e horizonte de planejamento finito (Pacheco e Morabito, 2011), comparação entre duas metodologias computacionais para deter- 
minar a política de gestão de caixa, tomando como base a estrutura do modelo proposto por Miller $e$ Orr (Moraes e Nagano, 2013), apresentar método para empreiteiros para avaliar pontualidade e plenitude de pagamentos ao proprietário com base no comportamento histórico (Tran e Carmichael, 2013) e verificação de práticas internacionais de gestão de caixa em uma empresa multinacional russa (Tsamenyi e Skliarova, 2015).

Além disso, é possivel encontrar as mais variadas ferramentas aplicadas à gestão de pagamentos $e$ caixa, como inteligência artificial, $k$-means, clustering, redes neurais (Cheng, 2009), lógica fuzzy (Cheng, 2009; Yao, Chen e Lu, 2006), algoritmo genético (Moraes e Nagano, 2013; Cheng, 2009), otimização por enxame de partículas (Moraes e Nagano, 2013) e programação linear (Righetto, Morabito e Alem, 2016; Pacheco e Morabito, 2011; Lusa, Martinez-Costa e Mas-Machuca, 2012; Shapiro, 1978), dentre outras.

Quando analisadas sob um aspecto internacional, as pesquisas sobre gestão de pagamentos e caixa tendem a se concentrar sobre a determinação dos saldos ideais em moeda local, compensação multilateral e gestão central de tesouraria para ajudar a usar transações fora do balanço para investimentos de curto prazo e empréstimos interempresas, a fim de reduzir o custo de captação, custos de conversão de moeda e otimizar a renda de investimento de curto prazo (Menyah, 2005). No entanto, é possivel perceber que os modelos encontrados, em geral, não levam em consideração os valores e percepções dos decisores.

Além disso, a função de gestão de caixa das empresas foi modelada como um sistema hard, que enfatiza o desenvolvimento de conjuntos de pressupostos que levam a modelos otimizáveis. Uma visão alternativa é que a gestão de dinheiro, em uma grande corporação, é um sistema de atividade humana, e o problema de fornecer apoio à decisão útil para um gerente poderia fazer uso de uma metodologia de sistemas soft (Bell e Parker, 1985).

A metodologia soft se afasta de abordagens de otimização tradicionais para enfatizar a relevância ge- rencial e a exequibilidade, cujo objetivo é desenvolver um modelo de gestão de pagamentos e caixa no qual o proprietário do problema pode reconhecer este e, então, ser capaz de interagir com o modelo em um modo experimental para tratar vários elementos de seu problema (Bell e Parker, 1985).

\section{Metodologia da pesquisa}

\section{Enquadramento metodológico}

Quanto aos objetivos, esta pesquisa é classificada como exploratória, pois busca investigar os critérios a serem considerados na construção do modelo a ser proposto, com base na percepção do chefe da coordenadoria de contabilidade e finanças para gestão de pagamentos, da Unila, uma vez que a instituição não tem, de forma clara, os aspectos necessários e suficientes para gerir a gestão de pagamentos e caixa de forma proativa. Em relação aos procedimentos, é caracterizada como estudo de caso (Richardson, 1999), tendo em vista ser uma investigação empírica, em seu contexto da vida real, na Unila.

A abordagem do problema desta pesquisa é caracterizada como qualitativa e quantitativa (Richardson, 1999). É qualitativa porque aprofunda o conhecimento sobre o tema pesquisado durante a fase de estruturação do modelo, à medida que é necessário conhecer o contexto da coordenadoria de contabilidade e finanças onde a gestão de pagamentos e caixa é realizada, para poder identificar os aspectos pelos quais o desempenho será medido $e$ gerenciado; na fase de recomendação, quando se analisam os descritores (escalas ordinais - qualitativas - construídas na fase de estruturação) e se identificam as situações que comprometem o desempenho para a futura apresentação de sugestões de ações de melhoria. É quantitativa quando mensura os aspectos considerados relevantes segundo a percepção do decisor (chefe da coordenadoria de contabilidade e finanças) por meio da construção das escalas cardinais (quantitativas) para os descritores identificados (agora, então, denominados de critérios), identifica taxas de compensação que permitem a utilização da equação de agregação aditiva a fim de obter a avaliação global do desempenho 
da gestão de pagamentos da Unila e quando realiza o teste da análise de sensibilidade para verificar a robustez das taxas de compensação do modelo construído.

Para o desenvolvimento desta pesquisa, serão utilizados dados primários (Richardson, 1999) que foram coletados por meio de entrevistas semiestruturadas com o chefe da coordenadoria de contabilidade e finanças, da Unila, a fim de identificar a percepção dele quanto aos aspectos relevantes (necessários e suficientes) e inerentes à gestão de pagamentos e caixa.

\section{Procedimentos para a seleção do material para subsidiar o referencial teórico e o instrumento de intervenção selecionado}

O Knowledge Development Process-Constructivist (ProKnow-C) foi o instrumento utilizado para a seleção dos artigos que subsidiam o referencial teórico deste estudo, bem como dos artigos que abordam o instrumento de intervenção para a construção do modelo multicritério construtivista. Sua justificativa se dá por ser um processo estruturado que apresenta o objetivo da construção de conhecimento de um determinado assunto, com base nos interesses e delimitações do pesquisador que o operacionaliza (Ensslin, Ensslin e Pacheco, 2012; Ensslin, Ensslin e Pinto, 2013; Dutra, Ripoll-Feliu, Fillol, Ensslin e Ensslin, 2015; Thiel, Ensslin e Ensslin, 2017; Valmorbida e Ensslin, 2017; Marcis, Bortoluzzi, de Lima e da Costa, 2018).

Essa geração de conhecimento ocorre em todos as etapas do Proknow-C: (a) seleção de um Portfólio Bibliográfico $(\mathrm{PB})$ de artigos sobre o fragmento que representa o tema da pesquisa; (b) análise bibliométrica que identifica os destaques das características dos artigos do PB; (c) análise sistêmica que faz uma análise crítica dos artigos do $\mathrm{PB}$, por meio de uma afiliação teórica do pesquisador, e (d) identificação de lacunas e oportunidades de futuras pesquisas (Thiel, Ensslin e Ensslin, 2017). Para se atingir o objetivo desta pesquisa, foi feita apenas a seleção do PB, etapa (i) do Proknow-C, uma vez que os pesquisadores fizeram uso do processo para selecionar os artigos científicos relevantes e, assim, oferecer à comunidade científica materiais qualificados sobre o tema e sobre o instrumento que conduz a construção do modelo. Para tal, inicialmente, faz-se necessária a identificação das palavras-chave para a busca e das bases de dados nas quais os artigos são buscados.

A seleção do banco de artigos bruto, com o objetivo de selecionar o PB do fragmento da literatura sobre gestão de pagamentos e caixa, foi feita nas bases de dados Web of Science, Scopus, Proquest, Ebsco, Science Direct e Engineering Village. As palavras-chave utilizadas para o eixo gestão de pagamentos foram: payroll management, payment management, management of payment, managing payment, payrolls management, payments management, management of payments e managing payments; para o eixo gestão de caixa, foram: cash management, management of cash e managing cash. A busca foi feita no dia 12 de abril de 2018 e resultou em 4.413 publicações distribuídas entre as bases de dados. Destas, 402 se apresentaram com títulos alinhados. Após a leitura dos resumos, mantiveram-se 169 artigos. Verificados os que estavam disponiveis, foi obtido um total de 51 artigos. Após a leitura na integra, 28 foram considerados alinhados com o propósito desta pesquisa; seus autores são: Agundu, Okon e Robinson (2007); Bar-llan, Perry e Stadje (2004); Bell e Parker (1985); Caouch (2018); Chen (2012); Cheng, Tsai e Liu (2009); Enow e Kamala (2016); Knyazeva et al. (2016); Luo (2011); Khanzadi, Eshtehardian e Mokhlespour Esfahani (2017); Lusa, Martínez-Costa e Mas-Machuca (2012); Mao e Sarndal (1978); Menyah (2005); Miller e Orr (1966); Moraes e Nagano (2013); Moussawi-Haidar e Jaber (2013); Pacheco e Morabito (2011); Righetto, Morabito e Alem (2016); Shapiro (1978); Strydom e Stephen (2014); Salas-Molina, Rodríguez-Aguilar e Juan (2017); Salas-Molina, Pla-Santamaria e Rodriguez-Aguilar (2016); Su e Hildreth (2018); Tahir, Alifiah, Arshad e Saleem (2016); Tran e Carmichael (2013); Tsamenyi e Skliarova (2005); Yao, Chen e Lu (2005), e Wang et al. (2018).

A seleção do banco de artigos bruto, com o objetivo de selecionar o PB do fragmento da literatura sobre metodologia MCDA-C, foi feita nas bases de dados 
Web of Science, Scopus, Proquest, Ebsco, Science Direct e Engineering Village. As palavras-chave utilizadas para o eixo multicritério de apoio à decisão foram: Multicriteria, MCDA-C, MCDA, Decision aid, Decision aiding, Multi-criteria Method* e Multicriteria Method*; para o eixo construtivista, foi a palavra constructivist. A busca foi feita no dia 12 de abril de 2018 e resultou em um total de 111 publicações distribuídas entre as bases de dados.

Essas publicações foram analisadas quanto à duplicidade, sendo a base de dados reduzida para 48 artigos. Destes, 31 estavam disponíveis; após a leitura na integra, 24 foram considerados alinhados com o propósito desta pesquisa; seus autores são: Alves, Mairesse-Siluk, Neuenfeldt-Junior, Soliman e DallaNora (2015); Azevedo, Lacerda, Ensslin, Jungles e Ensslin (2013); Bortoluzzi, Ensslin e Ensslin (2010); Bortoluzzi, Ensslin e Ensslin (2011); Ensslin, Dutra e Ensslin (2000); Ensslin, Dutra, Ensslin, Longaray e Dezem (2016); Ensslin, Ensslin, Rocha, Marafon e Medaglia (2013); Ensslin, Giffhorn, Ensslin, Petri e Vianna (2010); Ensslin, Queiroz, Grzebieluckas, Ensslin, Nickel, Buson e Junior (2011); Ensslin, Carvalho, Gallon e Ensslin (2008); Ensslin, Dutra, Duarte, Bortoluzzi e Ripoll-Feliu (2014); Espinosa e Salinas (2013); Espinosa, e Salinas (2015); Ferreira, Spahr, Santos e Rodrigues (2012); Lacerda, Enssline Ensslin (2011a); Lacerda, Ensslin e Ensslin (2011b); Machado, Ensslin e Ensslin (2015); Ramos e Loch (2006); Reck e Schultz (2016); Rodrigues, Fernandes, Rodrigues, Bortoluzzi, Costa e Lima (2018); Silveira, Vianna, Cândido e Petri (2017); Tasca, Ensslin e Ensslin (2012); Zamcope, Ensslin e Ensslin (2012a); Zamcope, Ensslin e Ensslin (2012b).

\section{Coleta dos dados e procedimentos para a construção do modelo multicritério construtivista}

A metodologia MCDA-C busca a expansãode conhecimento do tomador de decisão quando em contextos complexos, conflitantes e incertos (Silveira, Vianna, Cândido e Petri, 2017; Tasca, Ensslin e Ensslin, 2012; Bortoluzzi, Ensslin e Ensslin, 2011). Para isso, investiga o contexto decisional a fim de desenvolver modelos nos quais os decisores possam ter bases para a tomada de decisão, no que eles acreditam ser o mais adequado (Bortoluzzi, Ensslin e Ensslin, 2011), considerando as percepções e valores dos envolvidos no processo (Ensslin et al., 2011; Ensslin et al., 2010; Ensslin, Dutra e Ensslin, 2000). Assim, o conhecimento construtivista considera o objeto pela visão do pesquisador (Roy, 1993).

A construção do modelo, na perspectiva da metodologia MCDA-C, ocorre com a interação direta $e$ constante do decisor com o facilitador. Nessa interação, a atividade de apoio à decisão se dá a partir do desenvolvimento das três fases da metodologia MCDA-C: (i) fase de estruturação; (ii) fase de avaliação e (iii) fase de elaboração de recomendações (Silveira, Vianna, Cândido e Petri, 2017; Ensslin, Dutra, Ensslin, Longaray e Dezem, 2016; Zamcope, Ensslin e Ensslin, 2012a; Zamcope, Ensslin e Ensslin, 2012b; Bortoluzzi, Ensslin e Ensslin, 2011; Ensslin et al., 2011; Ensslin et al., 2010; Ensslin, Dutra e Ensslin, 2000).

A fase de estruturação busca identificar, organizar e mensurar qualitativamente os aspectos relevantes a respeito da situação decisional e considerados necessários e suficientes pelo decisor para avaliar tal contexto (Silveira, Vianna, Cândido e Petri, 2017; Bortoluzzi, Ensslin e Ensslin, 2011, Ensslin et al., 2011; Ensslin et al., 2010; Ensslin, Dutra e Ensslin, 2000). Para tal, por meio de entrevistas interativas que estimulam o debate entre decisor e facilitador, ocorre a geração de conhecimento $e$ a aprendizagem sobre o contexto que o decisor pretende gerir. Assim, inicia-se o processo, identificando quem são os atores, o contexto decisório e o problema sobre o qual se deseja gerar conhecimento e construir $\mathrm{O}$ modelo. Posteriormente, em entrevistas semiestruturadas, passa-se à identificação de Elementos Primários de Avaliação (EPAs), que são preocupações manifestadas pelo decisor (Ensslin, Dutra e Ensslin, 2000). Os EPAs são constituídos de objetivos, metas, valores dos decisores, ações, opções e alternativas consideradas importantes pelo decisor (Ensslin et al., 2011; Ensslin et al., 2010; Ensslin, Dutra e Ensslin, 2000). Essas preocupações (EPAs) são transformadas em conceitos formados por dois polos: polo presente (indica a direção de preferência do decisor relacionada ao EPA) e o polo 
psicológico (indica o mínimo aceitável pelo decisor ou a situação que ele deseja evitar) (Bortoluzzi, Ensslin e Ensslin, 2011; Ensslin, Dutra e Ensslin, 2000). Esses conceitos são agrupados por afinidades em áreas de interesse, a partir das quais são construídos mapas cognitivos para cada área, em que novos conceitos podem emergir, ou conceitos já existentes podem ser excluídos. Com base nos mapas, elabora-se a Estrutura Hierárquica de Valor (ou Árvores de Pontos de Vista), que apresenta os objetivos estratégicos (denominados Pontos de Vista Fundamentais - PVFs) e seus desdobramentos até um nivel em que o objetivo possa ser mensurado (denominado Ponto de Vista Elementar - PVE). A mensuração ordinal ocorre pela construção dos descritores, que são um conjunto de níveis de impacto por meio de escalas ordinais que possibilitam a medição do desempenho das propriedades e das ações potenciais de cada PVE, que operacionalizam os objetivos apresentados nos mapas cognitivos (Machado, Ensslin e Ensslin, 2015; Ensslin et al., 2010; Ensslin, Dutra e Ensslin, 2000). Cada nivel de impacto representará o desempenho de uma ação potencial nesse objetivo. Para finalizar os descritores, são estabelecidos dois níveis de referência: bom e neutro. Desempenho acima do nível "bom" significa que a organização está em nível de excelência; abaixo do "neutro", significa que o desempenho está aquém do esperado; entre os dois níveis, a organização se encontra com desempenho competitivo (Ensslin et al., 2016; Zamcope, Ensslin e Ensslin, 2012a; Bortoluzzi, Ensslin e Ensslin, 2011; Ensslin et al., 2011; Ensslin et al., 2010; Ensslin, Dutra e Ensslin, 2000).

A fase de avaliação consiste na transformação do modelo construído qualitativamente na fase de estruturação em um modelo quantitativo. Para isso, faz-se necessário: (i) construir a função de valor que represente as preferências do decisor em relação a um determinado descritor (com base nessa transformação, passa a existir um critério), de tal forma a ser possivel proceder-se à avaliação local; (ii) identificar as taxas de compensação entre os critérios (objetivos + escalas ordinal e cardinal); (iii) identificar o perfil de desempenho da instituição (Ensslin et al., 2016; Zamcope, Ensslin e Ensslin, 2012a; Ensslin et al., 2011; Ensslin, Dutra e Ensslin 2000) e (iv) realizar a avaliação global, que consiste na agregação das avaliações locais em um critério único de sintese (Bortoluzzi, Ensslin e Ensslin, 2011). Neste trabalho, esse processo foi realizado com o auxílio do software Macbeth-scores. O Measuring Attractiveness by a Cathegorical Based Evaluation Technique (MACBETH) é um método para transformar escalas ordinais em cardinais e baseia-se em juízos absolutos sobre a diferença de atratividade entre dois niveis da escala ordinal (Ensslin et al., 2011). Observa-se que, quando da transformação das escadas ordinais em escalas cardinais, ao nível neutro é atribuído o valor "0" (zero), e ao nível bom é atribuído o valor "100" (cem). A diferença de atratividade entre os níveis, acima, abaixo ou entre os níveis de referência, é feita pelo método do julgamento semântico, por meio de comparações par a par e utilizando-se o software Macbeth-scores. Após isso, são identificadas as taxas de compensação que informam a importância relativa de cada critério para o modelo. As taxas de compensação também são definidas pelo julgamento semântico, com o auxílio do software Macbeth para a obtenção dos resultados. Ao se identificarem as taxas de compensação de cada critério, os valores de cada avaliação local podem ser transformados em valores para uma avaliação global por meio da seguinte equação:

$$
V(a)=\sum_{i=1}^{n} w_{i} X v_{i}(a)
$$

Em que:

$V(a)=$ valor do desempenho global do modelo proposto;

$v 1(a), v 2(a), \ldots v n(a)=$ valor parcial de desempenho do modelo proposto nos critérios 1,2 , n;

$w 1, w 2, \ldots w n=$ taxas de compensação nos critérios $1,2, \ldots \mathrm{n}$;

$n$ = número de critérios do modelo.

Com o resultado da equação, é possível avaliar o desempenho de forma numérica e a influência que cada critério apresenta em relação ao desempenho final. 
Para finalizar a fase de avaliação, faz-se a análise de sensibilidade que permite verificar a robustez ou não do modelo, ao analisar como o modelo responde a variações nas taxas de compensação dos critérios, o que possibilita identificar o intervalo de variação das taxas que não modifica o resultado final da avaliação (Zamcopé, Ensslin e Ensslin, 2012; Ensslin, Dutra e Ensslin 2000). Essa análise é importante, uma vez que o modelo é construído com base na percepção do decisor; assim, este pode, em alguns momentos em que expressa sua manifestação semântica (da diferença de atratividade da passagem de um nivel da escala ordinal para outro ou entre os critérios), estar incerto em seu julgamento (Zamcopé, Ensslin e Ensslin, 2012).

A equação abaixo permite identificar o intervalo de variação das taxas de compensação do modelo.

$$
W_{n}{ }^{\prime}=\frac{W_{n} \cdot\left(1-W_{1}{ }^{\prime}\right)}{\left(1-W_{1}\right)}
$$

Em que:

$w 1, w 2, \ldots w n=$ taxas de compensação nos critérios $1,2, \ldots \mathrm{n}$;

$n$ = número de critérios do modelo.

Finalizada a fase de avaliação, passa-se à fase de recomendações que consiste em apoiar o decisor com a sugestão de ações para melhorar o desempenho em relação à situação atual. Esse procedimento tem por base apoiar a melhora do desempenho da organização (i) nos critérios em que esta impactou em desempenho no nivel comprometedor; (ii) naqueles critérios cuja contribuição seja mais significativa e (iii) naqueles critérios cujas ações demandem recursos financeiros reduzidos ou nulos (Bortoluzzi, Ensslin e Ensslin, 2011). Cumpre salientar que a fase de recomendação auxilia a decisão no momento de selecionar qual alternativa implementar, bem como em qual alternativa seria mais vantajosa para alocar recursos escassos para alcançar melhor desempenho.

Como palavra final, a metodologia MCDA-C não pretende prescrever orientações, mas apenas auxiliar o decisor na construção (desenvolvimento) e análise de possiveis alternativas e no entendimento de suas consequências.

\section{Resultados - Construção do modelo de apoio à decisão}

Esta seção apresenta a construção do modelo multicritério de avaliação de desempenho-construtivista para apoiar a gestão de pagamentos e caixa, na Unila, informada pela metodologia MCDA-C. Está dividida nas seguintes subseções: fase de estruturação, fase de avaliação e fase de recomendações.

\section{Fase de estruturação}

Para a construção do modelo durante a primeira entrevista, procurou-se caracterizar o contexto decisório em que se buscava o apoio à decisão. Nessa entrevista, identificou-se que o chefe da Contabilidade e Finanças (gestor) realiza pagamentos na ordem de milhões de reais por mês para honrar os compromissos da Universidade. Entretanto, nem sempre os créditos são equivalentes às demandas (compromissos), o que vem ocorrendo devido aos repasses do Tesouro Nacional serem inferiores aos necessários, fazendo com que o gestor tenha de desenvolver processos para priorizar os pagamentos a fim de limitar os gastos ao caixa disponível. Adicionalmente, o gestor defronta-se com a situação de que a sociedade, os órgãos de controle, os superiores, pares e subalternos continuamente demandam esclarecimentos sobre a alocação dos recursos, induzin-

Quadro 1. Atores do modelo de gestão de pagamentos da Unila

\begin{tabular}{|c|c|c|}
\hline \multirow{2}{*}{$\begin{array}{l}\frac{w}{d} \\
\frac{d}{0} \\
\frac{\pi}{d} \\
\frac{d}{0} \\
\omega\end{array}$} & Decisor & $\begin{array}{l}\text { Contador - Chefe da Coordenadoria de } \\
\text { Contabilidade e Finanças (CCF) da Unila }\end{array}$ \\
\hline & Intervenientes & $\begin{array}{l}\text { Pró-reitor de Planejamento } \\
\text { Chefe do Departamento de Finanças } \\
\text { Chefe do Departamento de } \\
\text { Contabilidade }\end{array}$ \\
\hline \multicolumn{2}{|c|}{ Facilitadores } & Autores da pesquisa \\
\hline \multicolumn{2}{|c|}{ Agidos } & $\begin{array}{l}\text { Servidores lotados na CCF } \\
9 \text { servidores) (diretamente) } \\
\text { Fornecedores, servidores } \\
\text { e acadêmicos (indiretamente) }\end{array}$ \\
\hline
\end{tabular}

Fonte: dados da pesquisa. 
do o gestor a fundamentar as razões que o levaram a ranquear as demandas. Nesse contexto, o gestor necessita de um instrumento - modelo - de apoio à gestão financeira para que possa fundamentar o processo de priorização dos pagamentos da Unila.

Para a construção e legitimação do modelo, em entrevista subsequente, ficaram acordados os atores desse contexto, apresentados no Quadro 1.

Após a apresentação dos atores, definiu-se o seguinte rótulo: Modelo de Apoio à Gestão de Pagamentos para a Universidade Federal da Integração Latino-Americana. Com base no rótulo definido pelo chefe da Coordenadoria de Contabilidade e Finanças, passou-se a questioná-lo sobre os aspectos que ele considerava importante fazer para o modelo; ou seja, passou-se a indagar sobre os EPAs. Em entrevistas, foram identificados 36 EPAs e construídos seus conceitos. O Quadro 2 apresenta uma amostra desses cmonceitos. Na sequência, os conceitos são agrupados em áreas de preocupação por meio de análise de conteúdo. Para o modelo proposto, foram identificadas as áreas suporte, análise documental, juros e multa e stakeholders (Quadro 2).

Cumpre observar que a numeração atribuída aos EPAs foi aleatória, e os intervalos entre a numeração foi proposital devido à possibilidade de o EPA ser duplicado, triplicado, quadriplicado em caso de o decisor verificar mais conceitos relacionados ao mesmo EPA.

Com os conceitos organizados em áreas de preocupação, passa-se à construção dos mapas cognitivos. Para facilitar a interpretação desses mapas, seu conteúdo é analisado no intuito da identificação de clusters (delimitados pela linha tracejada) e subclusters (delimitado pelo nome atribuído pelo chefe do CCF, internamente ao cluster). A Figura 1 apresenta o fragmento dos clusters com seus subclusters.

Com base no conteúdo dos clusters e subcluster, eles são transformados na Estrutura Hierárquica de Valor (EHV), Figura 3, composta pelos PVFs) e seus desdobramentos em PVEs, que são passíveis de mensuração.

No modelo proposto, identificaram-se quatro PVFs (conforme a Figura 2), que, desdobrados, geraram 17 PVEs: "acompanhamento de recurso" e "controle de saldos", vinculado aos PVFs "suporte; "dias" e "processos não analisados", vinculado ao PVF "análise de documentação"; "processos parados" e "processos vencidos", vinculado ao PVF "juros e multa", e "inércia" e "impacto", vinculado ao "auxílio da bolsa no PVF stakeholders", "acompanhamento" e "impacto", vinculado a "bolsas diversas no PVF stakeholders", "acompanhamento

Quadro 2. Amostra de EPAs, conceitos e suas respectivas áreas de preocupação

\begin{tabular}{|c|l|l|l|}
\hline N.o & \multicolumn{1}{|c|}{ EPAs } & \multicolumn{1}{|c|}{ Conceitos } & \multicolumn{1}{|c|}{ Áreas de preocupação } \\
\hline 10 & Controle financeiro. & $\begin{array}{l}\text { Acompanhar recursos recebidos pelo Ministério da Educação. } \\
\text { Deixar de efetuar pagamentos. }\end{array}$ & Suporte \\
\hline 17 & $\begin{array}{l}\text { Acompanhamento das } \\
\text { liquidações de bolsas de } \\
\text { alimentação e moradia. }\end{array}$ & $\begin{array}{l}\text { Acompanhar o período em que as bolsas de alimentação e } \\
\text { moradia permanecem no setor de CCF. } \\
\text { Demonstrar incapacidade de gestão e controle de processos } \\
\text { perante os departamentos que demandam bolsas. }\end{array}$ & Stakeholders \\
\hline 20 & $\begin{array}{l}\text { Acompanhamento das } \\
\text { liquidações de diárias. }\end{array}$ & $\begin{array}{l}\text { Acompanhar o período em que as diárias permanecem no setor } \\
\text { de CCF ... Demonstrar incapacidade de gestão. }\end{array}$ & Stakeholders \\
\hline 52 & $\begin{array}{l}\text { Pagamento de multas e juros } \\
\text { devido a atrasos. }\end{array}$ & $\begin{array}{l}\text { Realizar os pagamentos nas datas dos vencimentos. } \\
\text { Pagar juros e multas. }\end{array}$ & Juros e multa \\
\hline 105 & Análise de documentação. & $\begin{array}{l}\text { Realizar análise da documentação. } \\
\text { Ter lançamentos equivocados. }\end{array}$ & Análise de documentação \\
\hline
\end{tabular}

Fonte: dados da pesquisa. 
Figura 1. Fragmento do mapa cognitivo em clusters e subclusters

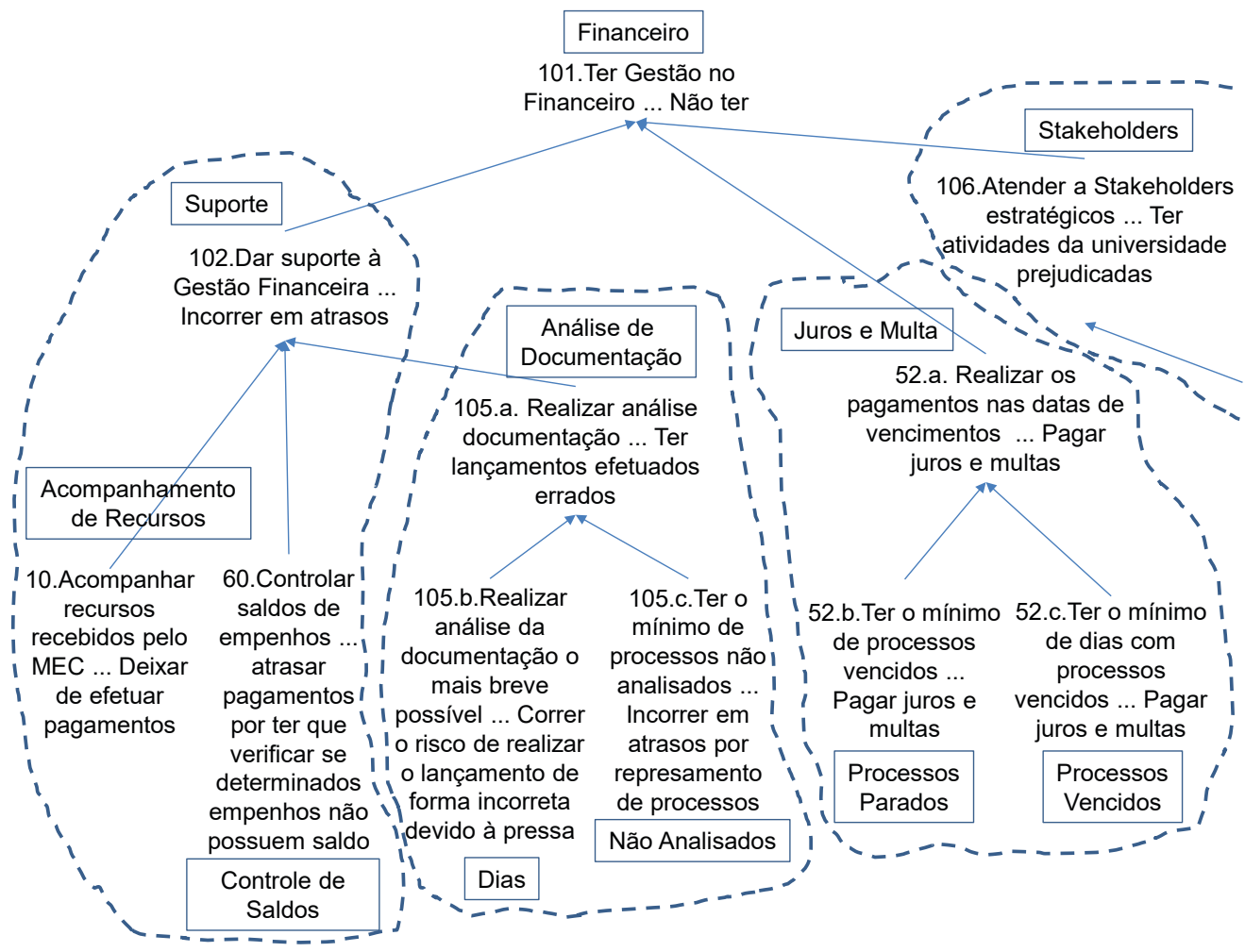

Fonte: dados da pesquisa.

de diárias", vinculado ao PVF "stakeholders", "atividades", "dificuldades" e "acompanhamento", vinculado aos "fornecedores do PVF stakeholders" $e$ "atividades", "dificuldades" e "acompanhamento", vinculado aos "terceirizados do PVF stakeholders".

Com base nos PVEs identificados, passa-se à construção das escalas ordinais. Assim, em entrevistas com o chefe da CCF da Unila, indagou-se sobre os níveis de desempenho aceitáveis para cada PVE. As escalas qualitativas construídas são denominadas, na metodologia MCDA-C, descritores. Conforme o número de PVEs, foram construídos 17 descritores (Figura 3).

Assim, para a preocupação "acompanhamento de recursos", que será avaliado pela periodicidade no acompanhamento dos recursos, o chefe da CCF identificou cinco possiveis niveis de impacto, quais sejam, por ordem de preferência: duas vezes ao dia, uma vez ao dia, três vezes na semana, duas vezes na semana e uma vez na semana. Após a construção da escala ordinal, o chefe do CCF identificou os niveis de referência. Para a preocupação "acompanhamento de recursos", considerou que o desempenho meta seria no acompanhamento uma vez ao dia, e o desempenho mínimo aceitável sem penalização seria duas vezes na semana, finalizando, assim, a construção dos descritores. Diante do modelo qualitativo construído, pode-se traçar o perfil de desempenho (statu quo) da atividade de gestão de pagamentos da Unila, conforme a Figura 3.

É possivel observar, na Figura 3, que os descritores dos PVEs "análise da documentação — não analisado", "juros e multa - processos vencidos", "bolsa- 
Figura 2. Estrutura hieráquica de valor



Fonte: dados da pesquisa.

auxílio - impacto", "bolsas diversas - impacto", "fornecedores - acompanhamento" e "terceirizados - acompanhamento" encontram-se com desempenho comprometedor para as atividades da organização, ou seja, 6 dos 17 descritores do modelo. Uma vez construídos os descritores (escalas qualitativas e ordinais), está finalizada a fase de estruturação. Passa-se então à fase de avaliação.

\section{Fase de avaliação}

O primeiro passo da fase de avaliação consiste em transformar as escalas ordinais em escalas cardinais, ou seja, identificar a função de valor de cada um dos descritores do modelo. Essa transformação consiste em identificar a intensidade de preferência do chefe do CCF com base nas diferenças de atratividade, de passar de um determinado nível da escala para outro nivel imediatamente inferior.

Essa atividade de traduzir a percepção do chefe do $\mathrm{CCF}$, quanto aos níveis de atratividade em valores matemáticos, foi facilitada pelo uso do software MACBETH (Measuring Attractiveness by Categorical Based Evaluation Technique). Para tal, o chefe do CCF explicitou, semanticamente, qual a perda percebida na passagem de um nível de desempenho da escala para outro, imediatamente inferior. Por exemplo, na Figura 4, pode-se visualizar que a perda de atratividade, considerada pelo chefe do CCF, de "acompanhar os recursos" uma vez ao dia, em vez de duas vezes ao dia, é por ele considerada "muito fraca".

Após o registro dos julgamentos semânticos do chefe do CCF, alimenta-se o software com a informação de quais são os niveis "neutro" e "bom" (sinalizados na Figura 4 nas cores verde e azul, respectivamente). Com base nessa informação, o software calcula a função de valor correspondente. Na Figura 4, pode ser visualizada a tela extraída do MACBETH após o preenchimento das manifestações do chefe do CCF quanto às diferenças de atratividade dos niveis do descritor "acompanhamento de recursos" 
Figura 3. Descritores e statu quo do modelo de gestão de pagamentos da Unila
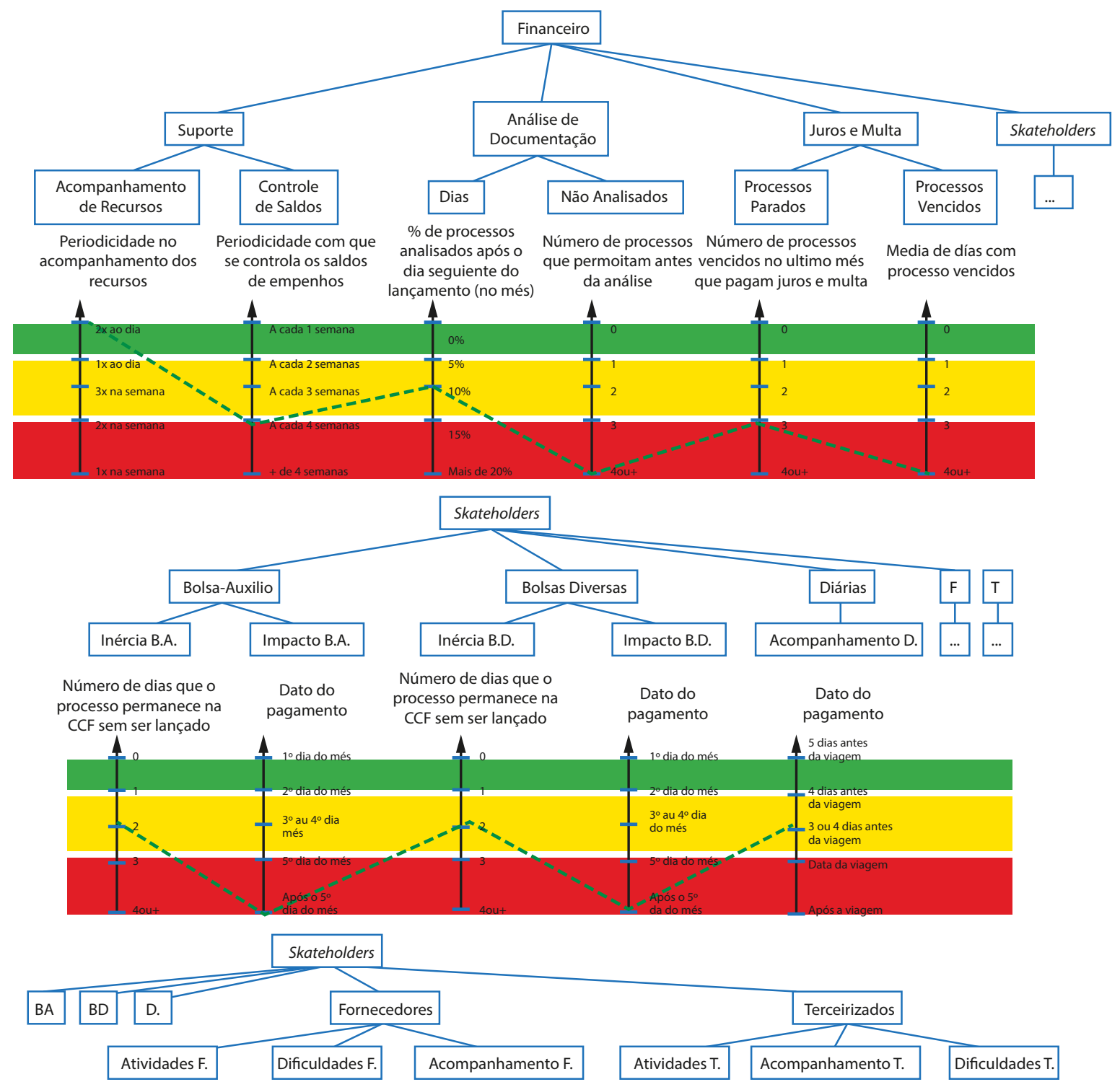

Grau em que as actividades Grau de dificuldade Tempo decorrido Grau em que as actividades Tempo decorrido Grau de dificuldade financeira da Universidade podem ser financeira que pode ser entre a data da da Universidade podem ser entre a data da da empresa que pode ser



Fonte: dados da pesquisa. 
(vinculado ao PVF suporte), bem como a respectiva função de valor, ou seja, a Figura 4 evidencia a transformação do descritor em critério.

Cumpre observar que todos os descritores foram transformados em critérios, respondendo assim à parte da pergunta de pesquisa e do objetivo. Com base nos critérios construídos, é possível proceder-se à avalição local do desempenho da atividade de gestão de pagamentos da Unila. Ou seja, na Figura 3, constata-se que o desempenho da Unila, no aspecto "acompanhamento de recursos", impacta no nível duas vezes ao dia; na Figura 4, percebe-se que o respectivo desempenho é avaliado em 140 pontos.

Para proceder-se à avaliação global do desempenho da gestão de pagamentos, necessita-se identificar as taxas de compensação de cada um dos 17 critérios do modelo. As taxas de compensação informam a importância relativa de cada critério no modelo.
Assim, as taxas de compensação, além de permitirem a agregação das avaliações locais em uma única avaliação global, também permitem conhecer a perda de desempenho que a CCF terá, em um critério, para compensar o ganho de desempenho em outro critério.

Essa atividade de identificação das taxas de compensação dos critérios foi inicialmente feita com o auxílio da matriz de ordenação dos critérios - Matriz de Roberts (parte superior esquerda da Figura 5), que usa a comparação par a par, em que o chefe do CCF manifesta sua preferência com relação à passagem do nivel "neutro" para o nivel "bom" para cada um dos critérios. Após os critérios estarem ordenados, o software MACBETH é alimentado para calcular as taxas de compensação. A Figura 5 demonstra a Matriz de Roberts, junto com a tela do software MACBETH e o fragmento do PVE "suporte", demonstrando os passos realizados.

Figura 4. Transformação do descritor "acompanhamento de recursos" em critério

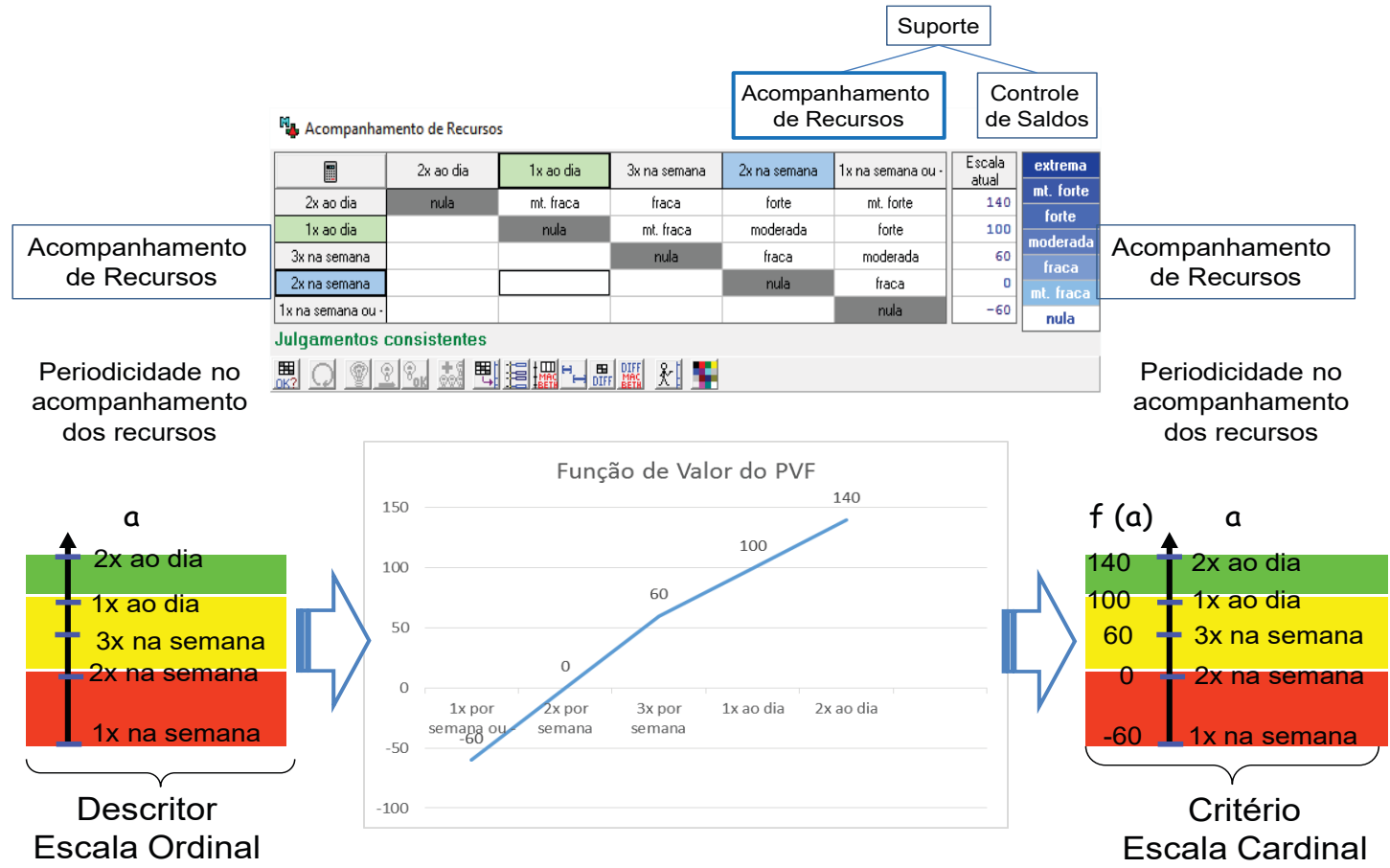

Fonte: dados da pesquisa. 
Observa-se, na Figura 5, que os procedimentos descritos geraram, para o "suporte", níveis de preferência de 60 \% para o PVE "acompanhamento de recursos", e 40 \% para o PVE "controle de saldos". O mesmo procedimento foi empregado para a determinação de todas as taxas de compensação entre os critérios e subcritérios da estrutura hierárquica de critérios.

Uma vez encontradas as taxas de compensação, encerra-se a etapa de avaliação, e o modelo está construído. Para se conhecer o desempenho, conforme o modelo proposto, e auxiliar na decisão, foram agregadas as avaliações locais das ações potenciais em uma única avaliação global, utilizando a fórmula de agregação aditiva (Ensslin et al., 2011; Ensslin et al., 2010; Ensslin, Dutra e Ensslin, 2000). Assim, para cada área de preocupação, por meio das seguintes equações:

$$
\begin{aligned}
& \text { Vsuporte (a) } \\
& \quad=[0,60 \mathrm{vD} 1(\mathrm{a})+0,40 \mathrm{v}(\mathrm{D} 2) \mathrm{a}] \\
& \begin{array}{r}
\text { VAnálise de documentos (a) } \\
\quad=[0,63 \mathrm{vD} 3(\mathrm{a})+0,37 \mathrm{v}(\mathrm{D} 4) \mathrm{a}] \\
\text { VJuros e multa (a) } \\
=[0,65 \mathrm{vD} 5(\mathrm{a})+0,35 \mathrm{v}(\mathrm{D} 6) \mathrm{a}] \\
\text { VStakeholders }(\mathrm{a})
\end{array}
\end{aligned}
$$

$$
\begin{aligned}
& =\left[0,28 *(0,65 v D 7(a)+0,35 v(D 8) a)+0,22^{*}\right. \\
& (0,65 v D 9(a)+0,35 v(D 10) a)+0,13(D 11)+ \\
& 0,17(0,42 \mathrm{D} 12+0,33 D 13+0,25 D 14)+ \\
& 0,20(0,42 \mathrm{D} 15+0,25 \mathrm{D} 16+0,33 \mathrm{D} 17)]
\end{aligned}
$$

Agregando à equação (2) as taxas de compensação dos PVFs, tem-se:

$\mathrm{V}(\mathrm{a})=0,22 *$ Vsuporte $(\mathrm{a})+0,21 *$ VAnálise de documentos(a) + 0,21*VJuros e multa(a) + 0,36 VStakeholders (a)

Dessa forma, agregando as equações 1,2 e 3 , junto às informações obtidas, conforme a Figura 5, tem-se:

$\mathrm{V}(\mathrm{a})=0,22 *(140 * 0,60+0 * 0,40)+0,21 *(60 *$ $0,63-60 * 0,37)+0,21 *(0 * 0,65-60 * 0,35)+$ $0,36 *(0,28 *(60 * 0,65-50 * 0,35)+0,22 *(60$

\begin{tabular}{|c|c|c|c|c|c|c|}
\hline \multicolumn{6}{|c|}{ Wु, Ponderação (Global) } & $-\infty$ \\
\hline$\square$ & [A1] & [A2] & [ tudo inf.] & $\begin{array}{l}\text { Escala } \\
\text { atual }\end{array}$ & extrema & \\
\hline [A1] & $\overline{\text { nula }}$ & moderada & extrema & 60 & $\mathrm{mt}$. forte & \\
\hline$[\mathrm{A} 2]$ & & nula & extrema & 40 & forte & \\
\hline [ tudo inf.] & & & nula & 0 & moderada & \\
\hline \multirow{2}{*}{\multicolumn{5}{|c|}{ Julgamentos consistentes }} & \begin{tabular}{|c|} 
fraca \\
mt. fraca
\end{tabular} & \\
\hline & & & & & nula & \\
\hline \multicolumn{7}{|c|}{  } \\
\hline
\end{tabular}
$* 0,65-50 * 0,35)+0,13 *(50)+0,17 *(0 * 0,42$ $+0 * 0,33-50 * 0,25)+0,20 *(0 * 0,42-50 *$ $0,25+0 * 0,33))=21,89$

A equação (4) demonstra que o desempenho da gestão de pagamentos, sob os valores do decisor, apresenta o resultado de 21,89 pontos em uma escala, conforme apresentado anteriormente, sendo o valor zero como neutro, e o valor 100 como bom.

Figura 5. Matriz de ordenação e taxas de compensação dos PVEs do PVF suporte

\begin{tabular}{|c|c|c|c|c|}
\hline & $\begin{array}{c}\text { Acomp. } \\
\text { Recursos }\end{array}$ & $\begin{array}{c}\text { Controle de } \\
\text { Saldos }\end{array}$ & Nulo & Total \\
\hline $\begin{array}{c}\text { Acomp. } \\
\text { Recursos }\end{array}$ & - & 1 & 1 & 2 \\
\hline $\begin{array}{c}\text { Controle de } \\
\text { Saldos }\end{array}$ & 0 & - & 1 & 1 \\
\hline Nulo & 0 & 0 & - & 0 \\
\hline
\end{tabular}

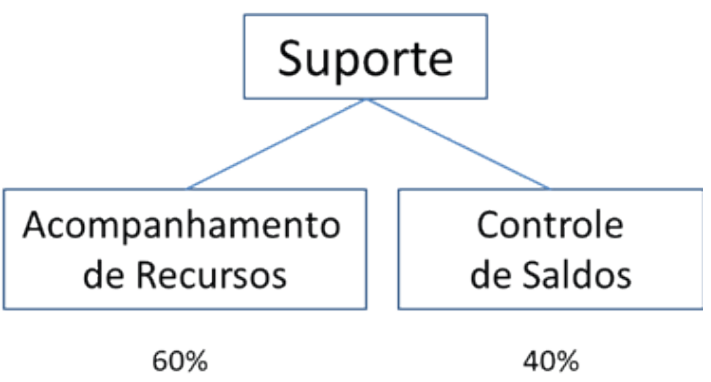

Fonte: dados da pesquisa. 
Por meio da fase de avaliação, após a identificação do statu quo, é possivel identificar, dentre as diversas possibilidades de emprego de recursos da organização (muitas vezes escassos), em quais das ações se atingirá melhor ou mais rápido o desempenho esperado pelo chefe da CCF, com base no modelo Multicritério, cujos parâmetros foram obtidos dos julgamentos do decisor.

Diante da possibilidade da existência de incertezas no julgamento do chefe do CCF da Unila, quando da construção do modelo Multicritério, e para demonstrar a consistência das informações do modelo, foi feita a análise de sensibilidade. Esta é demonstrada para o PVF suporte: PVE "acompanhamento de recursos" e PVE "controle dos saldos", aos quais, originalmente, se atribuíram as taxas de $60 \%$ e $40 \%$, respectivamente. A Figura 6 apresenta o intervalo de variação das taxas.

Figura 6. Análise de sensibilidade para os PVEs do PVF suporte

Análise da Sensibilidade de $V_{1}(S Q)$ para variações de $W_{1}$.

$$
\begin{array}{ll}
\frac{V_{1}(S Q)=0,60 V_{1.1}(S Q)+0,40 V_{1.2}(S Q)}{(1-0,60)}=1,00 \quad & V_{1}(S Q)=w_{1} \cdot(140)+w_{2}{ }^{*} 0= \\
& V_{1}{ }^{\prime}(S Q)=w_{1} \cdot(140)+w_{2}{ }^{\prime} 0=
\end{array}
$$

Para cada $1 \%$ de variação em $\mathrm{W}_{1}$ corresponde uma variação de $((140)-(0)) / 100 \%=1,4 / 1 \%$ pontos de $V_{1}(S Q)$.

Logo para uma variação de $20 \%$ em $w_{1}$ ( $20 \%$ de $60 \%=12 \%$ ) tem-se uma mudança em V1 (SQ) de

$12 \% * 1,4 / 1 \%=16,8$ pontos em $V_{1}(S Q)$.

Fonte: dados da pesquisa.

Portanto, pode-se concluir que as taxas são sensiveis a variações de percepções de "acompanhamento de recursos". Assim, variações nessa taxa podem provocar mudanças na avaliação do "statu quo - gestão de pagmentos da Unila”.

\section{Fase de recomendações}

Para a metodologia MCDA-C, a etapa de elaboração das recomendações tem o intuito de apoiar o uso do modelo Multicritério, construído onde se sugere que, inicialmente, seja procedida a verificação do desempenho atual (statu quo) nos aspectos em que o modelo desenvolvido se propõe a aperfeiçoar (Ensslin et al., 2010).

É possivel observar, na Figura 3, que os PVEs "análise da documentação - não analisado", "juros e multa - processos vencidos", "bolsa-auxílio - impacto", "bolsas diversas - impacto", "fornecedores - acompanhamento" e "terceirizados — acompanhamento" se encontram com desempenho comprometedor para as atividades da organização, ou seja, 6 dos 17 descritores do modelo. Além disso, apenas o descritor "suporte - acompanhamento de recursos" encontra-se com desempenho de excelência. A Tabela 1 apresenta os PVEs com desempenho comprometedor, a contribuição individual de cada descritor no modelo proposto, a pontuação no statu quo e qual impacto quando das mudanças para os níveis neutro e bom.

Alguns dos modos de escolha entre os critérios, que se possam alocar recursos para elevação de nível de desempenho, podem ser pelos critérios que se encontram em nivel comprometedor, pelos critérios que apresentem maior taxa de compensação ou critérios com menores custos/isentos de custos de melhoria, dentre outras alternativas.

Pela análise da equação (3), verifica-se que a área de preocupação stakeholders é a que apresenta maior taxa de compensação (36 \%). Dentre os critérios englobados pela área de preocupação stakeholders, bolsa-auxílio, bolsas diversas, diárias, fornecedores e terceirizados apresentam 28,00\%, $22,00 \%, 13,00 \%, 17,00 \%$ e 20,00 \%. Observase que a interação entre a área de preocupação stakeholders e o critério "bolsas diversas" representa aproximadamente $8 \%$ das preocupações do modelo multicritério (36\% * $22 \%$ ). Observa-se que o desempenho da CCF, no critério "bolsas diversas - impacto", se encontra em nivel comprometedor, estando sua preocupação inserida na análise apresentada.

Em relação às ações que não apresentam custos de serem implementadas, verifica-se que, para o critério "análise da documentação — não analisados", a implementação de ações de melhorias não geraria custos adicionais à instituição. 
Tabela 1. Critérios com desempenho comprometedor

\begin{tabular}{|l|c|c|c|c|}
\hline \multicolumn{1}{|c|}{ PVE/Critérios } & $\begin{array}{c}\text { Contribuição } \\
\text { individual }\end{array}$ & $\begin{array}{c}\text { Pontuação } \\
\text { statu quo }\end{array}$ & $\begin{array}{c}\text { Pontuação nível } \\
\text { neutro }\end{array}$ & $\begin{array}{c}\text { Pontuação nível } \\
\text { bom }\end{array}$ \\
\hline Análise documentação - não analisado & $7,77 \%$ & $\mathrm{~N} 5=-60$ & $\mathrm{~N} 4=0$ & $\mathrm{~N} 5=140$ \\
\hline Juros e multa - processos vencidos & $7,35 \%$ & $\mathrm{~N} 5=-60$ & $\mathrm{~N} 4=0$ & $\mathrm{~N} 5=140$ \\
\hline Bolsa-auxílio - impacto & $3,53 \%$ & $\mathrm{~N} 5=-50$ & $\mathrm{~N} 4=0$ & $\mathrm{~N} 5=125$ \\
\hline Bolsas diversas - impacto & $2,77 \%$ & $\mathrm{~N} 5=-50$ & $\mathrm{~N} 4=0$ & $\mathrm{~N} 5=125$ \\
\hline Fornecedores - acompanhamento & $1,53 \%$ & $\mathrm{~N} 5=-50$ & $\mathrm{~N} 4=0$ & $\mathrm{~N} 5=150$ \\
\hline Terceirizados - acompanhamento & $1,8 \%$ & $\mathrm{~N} 5=-50$ & $\mathrm{~N} 4=0$ & $\mathrm{~N} 5=150$ \\
\hline
\end{tabular}

Fonte: elaborado pelos autores.

Para as melhorias propostas, é possivel observar que, no PVE "bolsas diversas - impacto", a alteração do $\mathrm{N} 1$ para o $\mathrm{N} 2$ elevaria esse descritor de -50 pontos para zero, ou seja, uma alteração de 50 pontos, que influenciaria o desempenho global em 1,39 pontos. No caso da implementação das melhorias no PVE "análise da documentação - não analisadas", a alteração do N1 para o N5 elevaria esse descritor de -60 pontos para 140 pontos, ou seja, uma alteração de 200 pontos, influenciando o desempenho global em 15,54. Ao se implementarem as duas ações propostas, o desempenho global passaria de 21,89 pontos para 38,82 pontos. Haveria uma melhora de 77 \% em relação ao statu quo.

Ressalta-se que, conforme percepções do decisor, os PVEs "bolsas diversas - impacto" e "bolsas-auxílio - impacto" possuem formatos de controle similares, divergindo em relação aos pesos para o modelo proposto. Nesse caso, recomendam-se ações de melhoria similares para ambos os descritores. $\mathrm{O}$ mesmo ocorre com os PVEs "terceirizados - acompanhamento" e "fornecedores - acompanhamento".

Após os procedimentos feitos, o modelo construtivista para apoiar às decisões relacionadas à gestão de pagamentos da Unila está concluído. Portanto, responde-se à pergunta de pesquisa e ao objetivo do estudo.

\section{Considerações finais}

Aos considerar o ambiente dinâmico em que as organizações estão inseridas, a gestão de pagamentos pode apresentar complexidades e critérios que os decisores precisam levar em consideração. Aliado a cenários incertos, como o presenciado pelo Brasil após 2015, em que a Administração Pública Federal sofre as consequências da situação econômica em que o país atravessa, com a queda na arrecadação sem consequente diminuição de despesas, o apoio à decisão aos gestores dessas áreas tem sua importância e necessidades aumentadas.

Nesse contexto, esta pesquisa teve por objetivo construir um modelo multicritério de apoio à decisão, sob o viés construtivista, para avaliação do desempenho e apoio às decisões relacionadas à gestão de pagamentos, da Unila, sediada em Foz do Iguaçu, Brasil. Para isso, foi utilizada, como instrumento de intervenção, a metodologia MCDA-C, por se tratar de um problema que abrange fatores sociais e necessariamente abordagem participativa dos gestores $e$ dos atores envolvidos, sob o enfoque de um modelo não generalista, mas sim construtivista.

Por meio de entrevistas semiestruturadas, foram identificados 36 elementos primários de avaliação que, ao final do modelo, deram origem a 17 escalas ordinais e cardinais (qualitativas e quantitativas): critérios. Essas 17 representam as preocupações manifestadas pelo chefe da CCF para gestão de pagamentos e caixa, da Unila. Depois da construção das escalas, com os niveis de referência, pode-se traçar o perfil de desempenho (statu quo) em cada escala $e$, consequentemente, o perfil de desempenho da gestão de pagamento da instituição.

Foi possivel identificar, com base nos valores e preferências do decisor, que os critérios "análise da 
Quadro 3. Ações de recomendação

\begin{tabular}{|c|c|c|c|}
\hline $\begin{array}{l}\text { PVE: } \\
\text { Bolsas diversas — impacto }\end{array}$ & $\begin{array}{l}\text { Indicador: } \\
\text { Data do pagamento no mês }\end{array}$ & $\begin{array}{l}\text { PVE: } \\
\text { Análise da documentação - não } \\
\text { analisadas }\end{array}$ & $\begin{array}{l}\text { Indicador: } \\
\text { Número de processos que pernoitam } \\
\text { antes da análise }\end{array}$ \\
\hline \multicolumn{2}{|c|}{$\begin{array}{l}\text { Resultados esperado: espera-se que nenhum pagamento de bolsas } \\
\text { diversas seja realizado após } 05^{\circ} \text { dia do mês. }\end{array}$} & \multicolumn{2}{|c|}{$\begin{array}{l}\text { Resultados esperado: espera-se que nenhum processo ("0" — zero) pernoite } \\
\text { no setor de análise de documentação. }\end{array}$} \\
\hline \multicolumn{2}{|c|}{$\begin{array}{l}\text { Ações propostas: hierarquizar a prioridade dos pagamentos. } \\
\text { Dar prioridade ao pagamento das bolsas-auxílio antes dos demais } \\
\text { desembolsos. }\end{array}$} & \multicolumn{2}{|c|}{$\begin{array}{l}\text { Ações propostas: } \\
\text { Dar prioridade ao pagamento das bolsas-auxílio } \\
\text { antes dos demais desembolsos. }\end{array}$} \\
\hline \multicolumn{2}{|c|}{$\begin{array}{l}\text { Responsável: chefe do departamento financeiro } \\
\text { Prazo de atendimento: mensal }\end{array}$} & \multicolumn{2}{|c|}{$\begin{array}{l}\text { Responsável: chefe do setor SEREOF } \\
\text { Prazo de Atendimento: diário }\end{array}$} \\
\hline \multicolumn{2}{|c|}{ Impacto no descritor: passaria do N1 para o N2 } & \multicolumn{2}{|c|}{ Impacto no descritor: passaria do N1 para o N5 } \\
\hline \multicolumn{2}{|c|}{$\begin{array}{l}\text { Como acompanhar: acompanhamento mensal da data em que o pa- } \\
\text { gamento foi feito. }\end{array}$} & \multicolumn{2}{|c|}{$\begin{array}{l}\text { Como acompanhar: acompanhamento diário, ao final do expediente, de quan- } \\
\text { tos processos deixaram de ser analisados. }\end{array}$} \\
\hline
\end{tabular}

\begin{tabular}{|c|c|c|c|}
\hline $\begin{array}{l}\text { PVE: } \\
\text { Juros e multa - processos ven- } \\
\text { cidos }\end{array}$ & $\begin{array}{l}\text { Indicador: média de dias com } \\
\text { processos vencidos }\end{array}$ & $\begin{array}{l}\text { PVE: } \\
\text { Terceirizados - acompanha- } \\
\text { mento }\end{array}$ & $\begin{array}{l}\text { Indicador: tempo decorrido entre data da } \\
\text { nota e pagamento }\end{array}$ \\
\hline \multicolumn{2}{|c|}{$\begin{array}{l}\text { Resultados esperado: espera-se que a média de dias com proces- } \\
\text { sos vencidos que seja obrigado o pagamento de juros e multa seja } \\
\text { inferior a três por mês. }\end{array}$} & \multicolumn{2}{|c|}{$\begin{array}{l}\text { Resultados esperado: espera-se que o tempo decorrido entre a data da nota e } \\
\text { a data do pagamento seja inferior a } 90 \text { dias. }\end{array}$} \\
\hline \multicolumn{2}{|c|}{$\begin{array}{l}\text { Ações propostas: a partir do momento que um processo esteja } \\
\text { vencido, dar preferência para esse pagamento em detrimento dos } \\
\text { demais. }\end{array}$} & \multicolumn{2}{|c|}{$\begin{array}{l}\text { Ações propostas: } \\
\text { dar prioridade ao pagamento de processos, cuja nota fiscal esteja se aproxi- } \\
\text { mando de } 90 \text { dias da data de emissão. }\end{array}$} \\
\hline \multicolumn{2}{|c|}{$\begin{array}{l}\text { Responsável: chefe do departamento financeiro } \\
\text { Prazo de atendimento: diário }\end{array}$} & \multicolumn{2}{|c|}{$\begin{array}{l}\text { Responsável: chefe do departamento financeiro } \\
\text { Prazo de atendimento: diário }\end{array}$} \\
\hline \multicolumn{2}{|c|}{ Impacto no descritor: passaria do N1 para o N2 } & \multicolumn{2}{|c|}{ Impacto no descritor: passaria do N1 para o N2 } \\
\hline \multicolumn{2}{|c|}{$\begin{array}{l}\text { Como acompanhar: acompanhamento diário do conjunto de pro } \\
\text { sos, por data de vencimento e acompanhamento após o vencim } \\
\text { dos processos. }\end{array}$} & \multicolumn{2}{|c|}{$\begin{array}{l}\text { Como acompanhar: acompanhamento diário dos processos com data de } \\
\text { emissão com até } 90 \text { dias. }\end{array}$} \\
\hline
\end{tabular}

Fonte: dados da pesquisa.

documentação - não analisado", "juros e multa - processos vencidos", "bolsa-auxílio - impacto", "bolsas diversas - impacto", "fornecedores - acompanhamento" e "terceirizados - acompanhamento" (6 dos 17 critérios) se encontram com desempenho comprometedor para as atividades da Coordenadoria. Para esses, foram identificadas ações de melhoria na fase de recomendações.

O modelo multicritério proposto foi legitimado pelo chefe da CCF em todas as fases de sua construção. Ao término de sua elaboração, o decisor obteve uma ferramenta formal para ser usada como instrumento de apoio à decisão e avaliação de desempenho da gestão de pagamentos da Unila. É importante levar em conta que a metodologia multicritério, empregada neste estudo, adota uma abordagem construtivista.

Apesar de as organizações com restrição na disponibilidade de caixa apresentarem gastos mais eficientes (Lou, 2012), por meio deste trabalho, foi possivel verificar que os gestores necessitam de um modelo de apoio à decisão que leve em consideração suas preferências e valores.

Um dos trabalhos que se assemelha a este é o de Bell e Parker (1985), que, ao propor seu modelo, mantém contato direto com o decisor, sem predizer um modelo ideal sob uma perspectiva pragmática 
positivista. No entanto, seu modelo é direcionado para a gestão do fluxo de caixa, sob a forma visualmente gráfica, não se preocupando com períodos de escassez dos recursos. Da mesma forma que Bell e Parker (1985), em seu modelo visual interativo, a metodologia MCDA-C fornece um veículo para um novo olhar sobre velhos problemas, pois aumenta o envolvimento do decisor levando-o a projetar o modelo.

O trabalho apresenta, como contribuição teórica, a capacidade de pormenorizar todas as etapas em que se desenvolve o emprego da metodologia MCDA construtivista e identificar escalas ordinais (descritores), ou critérios (indicadores) de desempenho, que satisfizessem os valores e preferências do decisor, satisfação esta não encontrada nos modelos previamente elencados. Como contribuição prática, a pesquisa permitiu ao decisor participar de todas as fases da elaboração do modelo, o que proporcionou mais conhecimento da situação complexa na qual estava inserido e, ao mesmo tempo, trouxe legitimidade ao modelo construído.

Este estudo tem como limitação a construção de um modelo de apoio à decisão, personalizado para a gestão de pagamento da Unila. Nesse sentido, ao considerar que o modelo foi construído para atender às condições específicas do ambiente objeto do estudo, esse não é passivvel de generalizações. Para pesquisas futuras, sugerem-se (i) a utilização da metodologia MCDA-C nos demais setores da Unila; (ii) o desenvolvimento de modelos para a gestão de pagamentos de outras instituições que se apresentem com a situação de restrição financeira similar, para possiveis comparações de descritores construídos, e (iii) o acompanhamento da utilização do modelo por parte da instituição, a fim de verificar em que momento ele deixa de atender às necessidades inicialmente encontradas.

\section{Referências}

Agundu, P. U. C., Okon, G. B., \& Robinson, E. T. (2007). Cash management and revitalization of public medical centres in Nigeria: a strategic analysis. Journal Of Hospital Marketing \& Public Relations, 18(1), 71-79.

Alves, V. T., Mairesse-Siluk, J. C., Neuenfeldt-Júnior, A. L., Soliman, M., \& Dalla-Nora, L. D. (2015). Performance assessment of internal logistics for service companies. Revista Facultad de Ingeniería Universidad de Antioquia, (74), 188-199.

Azevedo, R. C., Lacerda, R. T. O., Ensslin, L., Jungles, A. E., \& Ensslin, S. R. (2013). Performance measurement to aid decision making in the budgeting process for apartment-building construction: Case study using MCDA-C. Journal of Construction Engineering and Management, 139(2), 225-235.

Bar-Ilan, A., Perry, D., \& Stadje, W. (2004). A generalized impulse control model of cash management. Journal of Economic Dynamics and Control, 28(6), 1013-1033.

Bell, P. C., \& Parker, D. C. (1985). Developing a visual interactive model for corporate cash management. Journal of the Operational Research Society, 36(9), 779-789.

Bortoluzzi, S. C., Ensslin, S. R., \& Ensslin, L. (2010). Performance evaluation of tangible and intangible aspects of the market area: A case study in a medium industrial company. Revista Brasileira de Gestão de Negócios, 12(37), 425-446.

Bortoluzzi, S. C., Ensslin, S. R., \& Ensslin, L. (2011). Multicriteria performance evaluation as an aid for management of companies: Implementation in a service company. Gestão e Produção, 18(3), 633-650.

Castro, C. M. (1977). A prática da pesquisa. São Paulo: McGrawHill do Brasil.

Chaouch, B. A. (2018). Analysis of the stochastic cash balance problem using a level crossing technique. Annals of Operations Research, 1-16.

Chen, H. L. (2012). Empirical behavioral analysis of project contractors' supply-chain payment terms. Supply Chain Management, 17(3), 277-289.

Cheng, M.-Y., Tsai, H.-C., \& Liu, C.-L. (2009). Artificial intelligence approaches to achieve strategic control over project cash flows. Automation in Construction, 18(4), 386-393.

Dutra, A., Ripoll-Feliu, V. M., Fillol, A. G., Ensslin, S. R., \& Ensslin, L. (2015). The construction of knowledge from the scientific literature about the theme seaport performance evaluation. International Journal Productivity and Performance Management, 64(2), 243-269.

Enow, S. T., \& Kamala, P. (2016). Cash management practices of small, medium and micro enterprises in the Cape Metropolis, South Africa. Investment Management and Financial Innovations, 13(1), 230-236.

Ensslin, L., Dutra, A., \& Ensslin, S. R. (2000). MCDA: a constructivist approach to the management of human resources at a governmental agency. International Transactions in Operational Research, 7(1), 79-100.

Ensslin, L., Ensslin, S. R., \& Pacheco, G. C. (2012). Um estudo sobre segurança em estádios de futebol baseado na análise bibliométrica da literatura internacional. Perspectivas em Ciência da Informação (Impresso), 17, 71-91.

Ensslin., L., Ensslin, S. R., \& Pinto, H. de M. (2013). Processo de investigação e Análise bibliométrica: Avaliação da Qualidade dos Serviços Bancários. RAC - Revista de Administração Contemporânea, 17(3), 325-349.

Ensslin, L., Dutra, A., Ensslin, S. R., Longaray, A. A., \& Dezem, V. (2016). Constructivist model of bank management support. Espacios, 37(9). 
Ensslin, L., Ensslin, S. R., Rocha, S., Marafon, A. D., \& Medaglia, T. A. (2013). Multi-criteria decision-aid constructivist model in the supplier evaluation process. Produção, 23(2), 402-421.

Ensslin, L., Giffhorn, E., Ensslin, S. R., Petri, S. M., \& Vianna, W. B. (2010). Performance evaluation of third party companies using the methodology of multicriteria decision supportconstructivist. Pesquisa Operacional, 30(1), 125-152.

Ensslin, L., Queiroz, S., Grzebieluckas, C., Ensslin, S. R., Nickel, E., Buson, M. A., \& Junior, A. B. (2011). Identification of costumers needs in the products development process: An innovative proposal illustrated for the automotive industry. Produção, 21(4), 555-569.

Ensslin, S. R., de Carvalho, F. N., Gallon, A. V., \& Ensslin, L. (2008). A multicriteria methodology (MCDA-C) to support the management of corporate intellectual capital. RAM. Revista de Administração Mackenzie, 9(7), 136-162.

Ensslin, S. R., Dutra, A., De Souza-Duarte, C., Bortoluzzi, S. C., \& Ripoll-Feliu, V. M. (2014). The evaluation of performance as a proposal for the management of teams of the Brazilian program "family health strategy" (FHS). Revista Gerencia y Politicas de Salud, 13(26), 10-25.

Espinosa, F. F., \& Salinas, G. E. (2013). Selection of improvement strategies for working condition for to maintenance function using constructivist multicriteria decision aid approach MCDA. Informacion Tecnologica, 24(3), 57-72.

Espinosa, F. F., \& Salinas, G. E. (2015). Definition of the Information Requirements and Functions for Maintenance Management through a Process of Constructive Analysis. Información Tecnológica, 26(6), 65-76.

Ferreira, F. A. F., Spahr, R. W., Santos, S. P., \& Rodrigues, P. M. (2012). A multiple criteria framework to evaluate bank branch potential attractiveness. International Journal of Strategic Property Management, 16(3), 254-276.

Khanzadi, M., Eshtehardian, E., \& Mokhlespour Esfahani, M. (2017). Cash flow forecasting with risk consideration using Bayesian Belief Networks (BBNS). Journal of Civil Engineering and Management, 23(8), 1045-1059.

Knyazeva, E., Yuzvovich, L., Smordina, E., Fomenko, V., \& Katochikov, V. (2016). Cash flow management at the insurance company aimed at provision of financial stability. American Journal of Applied Sciences, 13(6), 794-803.

Lacerda, R. T. O., Ensslin, L., \& Ensslin, S. R. (2011a). A performance measurement framework in portfolio management: A constructivist case. Management Decision, 49(4), 648-668.

Lacerda, R. T. O., Ensslin, L., \& Ensslin, S. R. (2011b). A performance measurement view of IT project management. International Journal of Productivity and Performance Management, 60(2), 132-151.

Luo, M. M. (2011). A bright side of financial constraints in cash management. Journal of Corporate Finance, 17(5), 1430-1444.

Lusa, A., Martínez-Costa, C., \& Mas-Machuca, M. (2012). An integral planning model that includes production, selling price, cash flow management and flexible capacity. International Journal of Production Research, 50(6), 1568-1581.

Machado, T. P. S. O., Ensslin, L., \& Ensslin, S. R. (2015). Product development using the MCDA-C approach. Produção, 25(3), 542-559.
Mao, J. C. T., \& Sarndal, C. E. (1978). Cash Management: Theory And Practice. Journal of Business Finance \& Accounting, 5(3), 329-338.

Marcis, J., Bortoluzzi, S. C., de Lima, E. P., \& da Costa, S. E. G. (2018). Sustainability performance evaluation of agricultural cooperatives' operations: a systemic review of the literature. Environment, Development and Sustainability. doi:10.1007/ s10668-018-0095-1

Martins, V. A. (2015). Proposta de um Mapa Estratégico para uma Universidade Pública. Revista Evidenciação Contábil \& Finanças, 3(2), 88-103.

Menyah, K. (2005). International Cash Management in the 21st century: Theory and Practice. Managerial Finance, 31(10), 3-17.

Miller, M. H., \& Orr, D. (1966). A model of the demand for money by firms. Quarterly Journal of Economics, 80(3), 413-435.

Moraes, M. B. d. C., \& Nagano, M. S. (2013). Cash management policies by evolutionary models: a comparison using the MillerOrr model. Journal of Information Systems and Technology Management, 10(3), 561.

Moussawi-Haidar, L., \& Jaber, M. Y. (2013). A joint model for cash and inventory management for a retailer under delay in payments. Computers and Industrial Engineering, 66(4), 758-767.

Pacheco, J. V. D., \& Morabito, R. (2011). Application of network flow models for the cash management of an agribusiness company. Computers \& Industrial Engineering, 61(3), 848-857.

Ramos, P. R., \& Loch, C. (2006). Using MCDA for a Water Resource Management? Application in Brazil. Journal of Decision Systems, 15(2-3), 197-213.

Reck, Â. B., \& Schultz, G. (2016). Aplicação da Metodologia Multicritério de Apoio à Decisão no Relacionamento Interorganizacional na Cadeia da Avicultura de Corte. Revista de Economia e Sociologia Rural, 54(4), 709-728.

Righetto, G. M., Morabito, R., \& Alem, D. (2016). A robust optimization approach for cash flow management in stationery companies. Computers \& Industrial Engineering, 99(C), 137-152.

Rodrigues, A. P., Fernandes, M. L., Rodrigues, M. F. F., Bortoluzzi, S. C., da Costa, S. G., \& de Lima, E. P. (2018). Developing criteria for performance assessment in municipal solid waste management. Journal of Cleaner Production, 186, 748-757.

Roy, B. Decision science or decision-aid science? (1993). European Journal of Operational Research, 66(2), 184-203.

Salas-Molina, F., \& Rodríguez-Aguilar, J. A. (2017). Data-driven multiobjective decision-making in cash management. EURO Journal on Decision Processes, 1-15.

Salas-Molina, F., Pla-Santamaria, D., \& Rodriguez-Aguilar, J. A. (2016). A multi-objective approach to the cash management problem. Annals of Operations Research, 1-15.

Shapiro, A. C. (1978). Payments netting in international cash management. Journal of International Business Studies, 9(2), 51-58.

Silveira, M. M., Vianna, W. B., Cândido, A. C., \& Petri, S. M. (2017). Estruturação de elementos formais para implantação 
de Gestão da Inovação em Bibliotecas. Informação \& Sociedade, 27(3).

Su, M., \& Hildreth, W. B. (2018). Does Financial Slack Reduce Municipal Short冈Term Borrowing?. Public Budgeting \& Finance, 38, 95-113.

Strydom, B., \& Stephen, T. (2014). Financial management in non-profit organisations: An exploratory study. Mediterranean Journal of Social Sciences, 5(15), 55-66.

Tahir, M. S., Alifiah, M. N., Arshad, M. U., \& Saleem, F. (2016). Financial theories with a focus on corporate cash holding behavior: A comprehensive review. International Journal of Economics and Financial Issues, 6(3), 215-219.

Tasca, J. E., Ensslin, L., \& Ensslin, S. R. (2012). Evaluation of training programs: A case study in public administration. Revista de Administração Pública, 46(3), 647-675.

Thiel, G. G., Ensslin, S. R., \& Ensslin, L. (2017) Street Lighting Management and Performance Evaluation: Opportunities and Challenges. Lex Localis - Journal of Local Self-Government, 15(2), 303-328.
Tran, H., \& Carmichael, D. G. (2013). A contractor's classification of owner payment practices. Engineering, Construction and Architectural Management, 20(1), 29-45.

Tsamenyi, M., \& Skliarova, D. (2005). International Cash Management Practices in a Russian Multinational. Managerial Finance, 31(10), 48-64.

Valmorbida, S. M. I., \& Ensslin, S. R. (2017). Performance Evaluation of University Rankings: Literature Review and guidelines for future research. International Journal of Business Innovation Research, 14(4), 479-501.

Yao, J. S., Chen, M. S., \& Lu, H. F. (2005). A fuzzy stochastic single-period model for cash management. European Journal of Operational Research, 170(1), 72-90.

Wang, Z., Xu, G., Zhao, P., \& Lu, Z. (2018). The optimal cash holding models for stochastic cash management of continuous time. Journal of Industrial \& Management Optimization, 14(1), 1-17.

Zamcopé, F. C., Ensslin, L., \& Ensslin, S. R. (2012). Construction of a model for corporate sustainability assessment: A case study in the textile industry. Gestão e Produção, 19(2),303-321. 